\title{
MECHANISM OF ANTI-IMPLANTATION ACTION OF CLOMIPHENE
}

\author{
M. R. N. PRASAD AND S. P. KALRA \\ Physiology of Reproduction Wing, Department of Zoology, \\ University of Delhi, Delhi 7, India \\ (Received 3rd January 1966, revised 1st March 1966)
}

\begin{abstract}
Summary. Clomiphene causes failure in implantation of blastocysts when administered to rats before implantation. This may be due either to a direct blastotoxic effect of the chemical or to elimination of blastocysts from the uterus. Further studies were made to elucidate the antiimplantation effect of the chemical. Clomiphene $(0.3 \mathrm{mg} / \mathrm{kg} /$ day $)$ was administered orally to rats on Day 9, Days 9 and 10, or Days 9,10 and 11 after mating during experimentally induced delayed implantation. Uterine horns were flushed $24 \mathrm{hr}$ after the last treatment. While $100 \%$ of the rats showed an average of four blastocysts/rat in initial controls, there was a marked reduction in the percentage $(37.5)$ of rats showing blastocysts and in the number of blastocysts recovered from uteri of treated rats, depending on the dose and the time interval allowed for action of the compound. Ligation of uterine horns at the cervical end before treatment resulted in recovery of normal numbers of blastocysts in $75 \%$ of rats. These results indicate that blastocysts are expelled from nonligated uteri. Initiation of oestrogen treatment ( $1 \mu \mathrm{g} / \mathrm{day}) 6,24$ and 48 $\mathrm{hr}$ after first administration of clomiphene failed to cause implantation of blastocysts in ligated uteri. However, normal numbers of implantation sites were seen in the ligated horns of controls. It is, therefore, conceivable that failure of implantation following clomiphene administration may be due: (a) to increased motility of the uterus resulting in expulsion of the blastocysts; (b) to its anti-oestrogenic and/or antihistaminic activity which prevents preimplantation changes in the uterus normally initiated by exogenously administered oestrogen. Our results show that clomiphene has no direct cytolytic effects on the blastocysts.
\end{abstract}

\section{INTRODUCTION}

In the search for antifertility agents attention has been focused on steroidal and non-steroidal compounds which either inhibit the development of the zygote (antizygotic agents) or prevent the implantation of the blastocyst (anti-implantation agents). Clomiphene, a non-steroidal compound structurally related to chlorotrianisene (TACE), inhibits fertility in female rats if administered during the tubal passage of fertilized eggs (Segal \& Nelson, 1961; Davidson, Wada \& Segal, 1965; Barnes \& Meyer, 1962). Prasad, Kalra \& 
Segal (1965), Davidson, Wada \& Segal (1965) and Schlough \& Meyer (1965a) showed that clomiphene causes failure of implantation in rats during experimentally produced delayed implantation or during lactational delay. Since blastocysts were not recovered from the uterus following clomiphene administration, Prasad et al. suggested that clomiphene had a direct blastotoxic action. The failure of implantation after clomiphene administration may also be due to the expulsion of ova from the uterus (Chang, 1964). The following experiments, reported here, were designed further to elucidate the precise mode of action of clomiphene on blastocysts during experimentally induced delayed implantation in non-lactating rats in an environment free from oestrogen.

\section{MATERIAL AND METHODS}

Colony-bred adult virgin female albino rats, originally derived from the Wistar strain, 150 to $180 \mathrm{~g}$ in weight were used. They were housed in air-conditioned rooms (the temperature was maintained at $78 \pm 2^{\circ} \mathrm{F}$ ) and fed a balanced diet; unlimited tap water was available. Two males and four females were caged together; vaginal smears were taken daily before 10.00 hours. Mating was confirmed by the presence of spermatozoa in vaginal smears which was considered as Day 1 of pregnancy. Mated females were separated from males. Delayed implantation was produced according to the method of Cochrane \& Meyer (1957). Ovaries were removed on Day 3 of pregnancy by the dorso-lateral approach and laparotomies were made by mid-ventral incision, all surgical procedures being done under ether anaesthesia. All the ovariectomized rats were injected with $4 \mathrm{mg}$ of progesterone in $0.25 \mathrm{ml}$ of oil daily from the day of ovariectomy until the termination of the experiment. The first laparotomy was performed on Day 8 after mating to determine whether implantation sites were present. Rats in which implantation sites were not seen were randomly distributed to different groups (Tables 1 and 2). Uterine horns were excised and flushed with $0.9 \%$ saline and the flushings examined for blastocysts under a stereoscopic microscope at a magnification of 40 . Clomiphene was administered by oral gavage at a dose of $0.3 \mathrm{mg} / \mathrm{kg} / \mathrm{ml}$ in olive oil. Oestradiol $(1 \mu \mathrm{g} / \mathrm{day})$ was injected subcutaneously for 5 days and rats were autopsied $24 \mathrm{hr}$ after the last injection. Uterine horns were ligated at the cervical end. The results were statistically analysed by the homogeneity $\chi^{2}$ test and Students $t$-test of Fisher (1958).

\section{RESULTS}

Tables 1 and 2 summarize the results of the experiments.

Daily injections of $4 \mathrm{mg}$ of progesterone to rats ovariectomized on Day 3 of pregnancy caused a delay in implantation of the blastocysts. The uteri of such rats (Table 1, Group 1) flushed on Day 9 post-coitum showed an average of four blastocysts each in $100 \%$ of the rats. In Groups 2, 3 and 4 (Table 1) clomiphene was administered on Day 9, Days 9 and 10, or Days 9, 10 and 11 and the uterine horns were flushed $24 \mathrm{hr}$ after the last treatment. Administration of one dose of clomiphene did not in any way alter the average number of blastocysts recovered or the percentage of animals showing blastocysts (Group 
$2)$. With the increase in dose and in time following the initiation of clomiphene treatment, namely for 2 days (Group 3 ) or for 3 days (Group 4), the percentage of rats with blastocysts in the uteri was reduced to 37.5 while the average number of blastocysts flushed was 3.6 and 2 respectively. The decrease in percentage of rats with blastocysts in Groups 3 and 4 (Table 1) was statistically significant $(P<0.01)$ compared to that in Groups 1 and 2 ; however, the average number of blastocysts/rat was significantly $(P<0.05)$ low only in Group 4, treated with clomiphene for 3 days. The gradual reduction in the percentage of rats with blastocysts and in the number of blastocysts/rat indicated the possibility of the elimination of blastocysts from the uterus. Uterine horns were, therefore, ligated at the cervical end on Day 9 of pregnancy and clomiphene was administered on Days 9 and 10, or Days 9, 10 and 11 (Table 1, Groups 6 and 7). In a control group olive oil was fed on Days 9 and 10 (Table 1, Group 5). Ligation of the uterine horns resulted in the recovery of blastocysts in $68.7 \%$

TABLE 1

EFFEGT OF GLOMIPHENE ON BLASTOCYSTS

\begin{tabular}{c|l|c|c|c|c}
\hline Group & \multicolumn{1}{|c|}{ Additional treatment* } & $\begin{array}{c}\text { No. } \\
\text { of } \\
\text { rats }\end{array}$ & $\begin{array}{c}\text { Day } \\
\text { of } \\
\text { autopsy }\end{array}$ & $\begin{array}{c}\text { Rats with } \\
\text { blastocysts } \\
(\%)\end{array}$ & Blastocysts/rat \\
\hline 1 & No treatment & 8 & 9 & 100 & $4 \cdot 0 \pm 0.72$ \\
2 & Clomiphene on Day 9 & 8 & 10 & 100 & $3 \cdot 8 \pm 0.47$ \\
3 & Clomiphene on Days 9 and 10 & 8 & 11 & $37 \cdot 5 \ddagger$ & $3 \cdot 6 \pm 1 \cdot 3$ \\
4 & Clomiphene on Days 9, 10 and 11 & 8 & 12 & $37.5 \ddagger$ & $2 \cdot 0 \pm 0.05 \dagger$ \\
\hline Uterine horns ligated on Day 9 & & & & \\
5 & Olive oil on Days 9 and 10 & 16 & 11 & $68 \cdot 7$ & $3 \cdot 6 \pm 0.44$ \\
6 & Clomiphene on Days 9 and 10 & 8 & 11 & $75 \cdot 0$ & $3 \cdot 8 \pm 0.87$ \\
7 & Clomiphene on Days 9, 10 and 11 & 8 & 12 & $75 \cdot 0$ & $4 \cdot 0 \pm 0.68$ \\
\hline
\end{tabular}

Dosage: Clomiphene $0.3 \mathrm{mg} / \mathrm{kg} / \mathrm{day}$.

* Rats ovariectomized on Day 3 of pregnancy and treated with $4 \mathrm{mg} /$ day of progesterone from day of ovariectomy until autopsy.

$+P<0.05$ compared to Group 1 .

$\ddagger P<0.01$ compared to Groups 1 and 2. The variation in percentage in Groups 5, 6 and 7 is not statistically significant, $P>0.05$.

of the olive oil fed controls (Group 5) and in $75 \%$ of the clomiphene-fed rats (Groups 6 and 7) with an average of 3.6, 3.8 and 4 blastocysts/rat respectively. This is similar to the number of blastocysts recovered from the uteri of the nonligated group (Group 1). There is an apparent decrease in the percentage of rats with blastocysts in the olive oil-fed group (Group 5) but this is statistically not significant $(P>0.05)$ from the percentages in the clomiphene-fed groups (Groups 6 and 7). Blastocysts recovered from the clomiphene-treated animals appeared morphologically normal.

Table 2 shows the inhibition of oestrogen-induced implantation following clomiphene administration. Oestrogen treatment was initiated 6, 24 and $48 \mathrm{hr}$ after the first feeding of clomiphene.

Administration of oestrogen to olive oil-fed controls (Table 2, Group 1) resulted in $75 \%$ of the rats showing implantation sites with an average of $3 \cdot 8 /$ rat. Initiation of oestrogen treatment $6 \mathrm{hr}$ after a single feeding of clomiphene

C 
resulted in one of the six rats showing four implantation sites (Group 2). There was complete failure of implantation in Groups 3 and 4 in which oestrogen treatment was begun $24 \mathrm{hr}$ or $48 \mathrm{hr}$ after the initial administration of clomiphene. In order to check the possibility that blastocysts forcibly retained in the uterus of clomiphene-fed rats might implant, uterine horns were ligated at the cervical end on Day 9. Administration of clomiphene and oestrogen (Groups 6, 7 and 8) followed a pattern similar to that in Groups 2, 3 and 4 (Table 2). In the controls (Group 5) treated with olive oil, $63.6 \%$ of the rats with uterine horns ligated at the cervix showed an average of $3.7 \mathrm{implantation}$ sites/rat comparable to the number of implantation sites in the non-ligated controls (Table 2, Group 1) and to the number of blastocysts recovered from the ligated uteri of olive oil- or

TABLE 2

EFFECT OF GLOMIPHENE ON IMPLANTATION OF BLASTOCYSTS

\begin{tabular}{c|l|c|c|c|c|c}
\hline Group & Additional treatment* & $\begin{array}{c}\text { Oestradiol (time } \\
\text { of initiation after } \\
\text { first feeding of } \\
\text { clomiphene or oil) } \\
(\mathrm{hr})\end{array}$ & $\begin{array}{c}\text { No. } \\
\text { of } \\
\text { rats }\end{array}$ & $\begin{array}{c}\text { Day } \\
\text { of } \\
\text { autopsy }\end{array}$ & $\begin{array}{c}\text { Rats with } \\
\text { sites } \\
(\%)\end{array}$ & Sites/rat \\
\hline 1 & Olive oil on Days 9, 10 and 11 & 72 & 8 & 17 & 75 & $3 \cdot 8 \pm 0 \cdot 67$ \\
2 & Clomiphene on Day 9 & 6 & 6 & 14 & $16 \cdot 6 \dagger$ & $4 \cdot 0$ \\
3 & Clomiphene on Days 9 and 10 & 24 & 5 & 15 & $0 \cdot 0$ & - \\
4 & Clomiphene on Days 9, 10 and 11 & 48 & 4 & 16 & $0 \cdot 0$ & - \\
\hline Uterine horns ligated on Day 9 & & & & & \\
5 & Olive oil on Days 9, 10 and 11 & 72 & 11 & 17 & 63.6 & $3 \cdot 7 \pm 0 \cdot 43$ \\
6 & Clomiphene on Day 9 & 6 & 6 & 14 & 0.0 & - \\
7 & Clomiphene on Days 9 and 10 & 24 & 6 & 15 & $0 \cdot 0$ & - \\
8 & Clomiphene on Days 9, 10 and 11 & 48 & 7 & 16 & $0 \cdot 0$ & - \\
\hline
\end{tabular}

Dosages: Clomiphene $0.3 \mathrm{mg} / \mathrm{kg} /$ day; oestradiol $1 \mu \mathrm{g} / \mathrm{day}$.

* Rats ovariectomized on Day 3 of pregnancy and treated with $4 \mathrm{mg} /$ day of progesterone from day of ovariectomy until autopsy.

$\dagger P<0.01$ compared to Group 1 .

clomiphene-fed rats (Table 1, Groups 5, 6 and 7); the variations in the values among these groups is not statistically significant $(P>0 \cdot 05)$. However, no implantation sites were seen in the clomiphene-fed rats (Table 2, Groups 6, 7 and 8$)$.

\section{DISCUSSION}

The antifecundity effects of clomiphene have been studied by a number of workers who have suggested the possibility that the failure of implantation may be due to a direct blastotoxic action of the chemical (Segal \& Nelson, 1961; Davidson, Wada \& Segal, 1965; Prasad et al., 1965). In discussing the causes of failure of implantation in clomiphene-fed rats Prasad et al. (1965) pointed out that the antigonadotrophic and anti-oestrogenic effects of clomiphene may not be responsible for the degeneration of the blastocysts during experimentally produced delayed implantation. However, they raised the question whether failure of implantation may be due to expulsion of blastocysts from the uterus as suggested by Chang (1964). 
The data presented in Table 1 demonstrate clearly the elimination of blastocysts from the uterus following clomiphene administration. While $100 \%$ of the rats showed an average of four blastocysts/rat in the control group (Table 1, Group 1) as well as in those receiving $0.3 \mathrm{mg} / \mathrm{kg}$ of clomiphene (Table 1, Group 2), a marked reduction in the percentage of rats showing blastocysts (Groups 3 and 4) and in the average number of blastocysts recovered from the uteri, occurred in Group 4, depending on the increase in dose and time interval allowed for action of the compound. The increase in percentage of rats showing blastocysts and the recovery of average numbers of blastocysts from the uteri of ligated rats treated with clomiphene (Table 1, Groups 6 and 7) indicate that the blastocysts were possibly being expelled from the uteri of non-ligated rats. A similar phenomenon may also account for the failure in our earlier work (Prasad et al., 1965) to recover blastocysts 5 days after clomiphene feeding and before the initiation of oestrogen treatment. These results are essentially in agreement with the observations of Greenwald (1957, 1959, 1961), Banik \& Pincus (1964), Pincus \& Banik (1963), Pincus, Banik \& Jacques (1964), Davis (1963) and Chang (1964), who showed that steroidal and non-steroidal compounds with oestrogenic activity cause the expulsion of eggs and blastocysts from the fallopian tube and uterus.

In order to understand the mode of action of clomiphene, it may be of interest to compare the antifertility effects of compounds derived from chlorotrianisene namely ethamoxytriphetol (MER-25), MRL-37 and clomiphene (MRL-41) with their known oestrogenic and anti-oestrogenic activities. MER-25 and MRL-37 are not oestrogenic at dose levels at which they show effective antifertility activity, an activity which may possibly be related to their anti-oestrogenic action (Emmens, 1965). These compounds do not affect the viability of the blastocysts (Schlough \& Meyer, 1965a). On the other hand, clomiphene exhibits antifertility and oestrogenic activities at the same low dose level (Emmens, 1965). The antifertility effects of clomiphene may possibly be due to the oestrogenicity of the compound (Kalra \& Prasad, unpublished observations).

It is clear from our data shown in Table 1 that blastocysts are expelled from the uterus following clomiphene administration. This may be due to the increased motility of the uterus caused by the oestrogenicity of the chemical at the low dose level of $0.3 \mathrm{mg} / \mathrm{kg}$ we have used. Davidson, Schuchner \& Wada (1965) observed accelerated passage of ova and blastocysts following administration of low doses of clomiphene. Oestrogens similarly cause the expulsion of ova/blastocysts from the reproductive tracts of pregnant animals (Noyes, Adams \& Walton, 1959; Greenwald, 1961; Deanesly, 1963; Chang, 1964; Harper, 1964; Banik \& Pincus, 1964). Schlough \& Meyer (1965a) noticed a few implantation sites following $0.3 \mathrm{mg} / \mathrm{kg}$ of clomiphene administered during delayed implantation. However, we have not obtained so far even a single case of implantation using the same dose of clomiphene under similar experimental design. Since oestrogen by itself causes implantation of blastocysts during experimentally induced delayed implantation, the failure of $0.3 \mathrm{mg} / \mathrm{kg}$ of clomiphene to initiate changes leading to implantation may be due to the oestrogenicity of the compound being too low at this dose level to trigger pre-implantation changes in the uterus. 
Since blastocysts were recovered from the uteri of clomiphene-fed rats after uterine ligation it was of interest to determine if such morphologically normal blastocysts forcibly retained in the uterus would implant following oestrogen administration. Initiation of oestrogen treatment $6 \mathrm{hr}$ after clomiphene administration (Table 2, Groups 2 and 6) resulted in implantation in only one rat, while in others (Groups 3, 4, 7 and 8), in which oestrogen was begun $24 \mathrm{hr}$ and $48 \mathrm{hr}$ after the first clomiphene feeding, failure of implantation was again the result. However, normal numbers of implantation sites were seen in the control groups (Table 2, Groups 1 and 5) comparable to the number of blastocysts recovered from the uteri of the rats in Groups 1, 2, 5, 6 and 7 shown in Table 1.

The failure of oestrogen-induced implantation of morphologically, apparently normal blastocysts raises the question as to whether this is due to an effect of clomiphene on the uterus preventing the nidation of blastocysts which may otherwise be viable. In any consideration of the mode of action of anti-implantation drugs it is essential to distinguish between a direct effect on the blastocyst and interference with the receptivity of the uterus for the blastocyst. Our results indicate that failure of oestrogen-induced implantation following clomiphene administration may be due to a decreased sensitivity of the uterus to oestrogen which otherwise prepares the uterus for implantation. Roy, Greenblatt \& Mahesh (1964), Roy, Mahesh \& Greenblatt (1964) and Lerner (1964) showed that clomiphene competes with oestrogen for binding sites in the uterus thus preventing the action of oestrogen injected subsequently. Shelesnyak (1957) has postulated that the pre-decidualization changes in the uterus are initiated by histamines which, in turn, are released by the action of oestrogens on the uterus; histamine-dependent decidual cell response may be prevented by antihistamines. Shelesnyak, Kraicer \& Zeilmaker (1963) inhibited decidual reaction in rats by administration of MER-25, $72 \mathrm{hr}$ after mating and suggested that the anti-oestrogenicity of the compound prevented the oestrogen surge from acting upon the uterus. Coppola (personal communication cited by Schlough \& Meyer, 1965a, b) has suggested, on the basis of the configuration of the aliphatic portion of the molecule, that the stilbendrel series of compounds are basically antihistamines and they possess a selective affinity for uterine receptor sites due to the oestrogen-like configuration of the aromatic portion. Schlough \& Meyer (1965a, b) suggested that the suppression of decidual cell response in the uterus by clomiphene may be due to its anti-histaminic activity based on: (a) the histamine-antihistamine relationship found in the uterus; (b) their molecular configuration; and (c) their ability to suppress albumininduced oedema-a histamine response. In our experiments, treatment with oestrogen, even within $6 \mathrm{hr}$ of the administration of clomiphene, prevented subsequent oestrogen-induced implantation of blastocysts retained within the uteri of clomiphene-fed rats. If clomiphene is acting like an anti-oestrogen and/or antihistamine, binding with receptor sites of the uterus, it may presumably be preventing further stimulation of the uterus by oestrogen exogenously injected subsequently.

On the basis of these observations it is conceivable that the failure of implantation following clomiphene administration may be due to a variety of 
factors: (a) clomiphene acting like a weak oestrogen may increase the motility of the uterus, resulting in the expulsion of the blastocysts; (b) at the same dose levels, due to its anti-oestrogenic and/or antihistaminic activities, clomiphene may compete with oestrogen for receptor sites in the uterus, thus preventing initiation of pre-implantation changes in the uterus by the subsequent action of exogenously administered oestrogen.

Note added in proof: Staples (1966) has provided convincing evidence to show that clomiphene does not have a direct cytotoxic action on the developing zygote. Blastocysts recovered from clomiphene-treated rats implanted and developed normally following transfer to the uteri of pseudopregnant untreated recipients. However, blastocysts from untreated females failed to survive in the uteri of clomiphene-fed rats. These results support our observations that clomiphene does not have a direct effect on the blastocyst but alters the internal milieu of the uterus and renders it hostile for the implantation of blastocysts.

\section{ACKNOWLEDGMENTS}

This investigation was supported by a grant from the Ford Foundation. The authors thank Dr B. R. Seshachar for his interest in this study. One of us (S.P.K.) is thankful to the Council of Scientific and Industrial Research, India, for the award of a Research Fellowship. We are grateful to Dr D. E. Holtkamp of Wm. S. Merrell Co. for the supply of clomiphene.

\section{REFERENCES}

Banik, U. K. \& Pincus, G. (1964) Estrogens and transport of ova in the rat. Proc. Soc. exp. Biol. Med. 116, 1032.

Barnes, L. E. \& MeYer, R. K. (1962) Effects of Ethamoxytriphetol, MRL-37, and clomiphene on reproduction in rats. Fert. Steril. 13, 472.

Chang, M. C. (1964) Effects of certain antifertility agents on the development of rabbit ova. Fert. Steril. 15, 97.

Cochrane, R. L. \& Meyer, R. K. (1957) Delayed nidation in the rat induced by progesterone. Proc. Soc. exp. Biol. Med. 96, 155.

Davidson, O. W., Schuchner, E. B. \& Wada, K. (1965) Effect of clomiphene on rat zygotes. Fert. Steril. 16, 495.

Davidson, O. W., WADA, K. \& SEGAL, S. J. (1965) Effects of clomiphene at different stages of pregnancy in the rat: Implication regarding possible action mechanisms. Fert. Steril. 16, 195.

Davis, B. K. (1963) Studies on the termination of pregnancy with norethynodrel. F. Endocr. $27,99$.

DeAnesLy, R. (1963) Further observations on the effects of oestradiol on the tubal eggs and implantation in the guinea-pig. F. Reprod. Fert. 5, 49.

Emmens, C. W. (1965) Oestrogenic, anti-oestrogenic and antifertility activities of various compounds. 7. Reprod. Fert. 9, 277.

Fisher, R. A. (1958) Statistical methods for research workers. Oliver \& Boyd, Edinburgh.

GREENWALD, G. S. (1957) Interruption of pregnancy in the rabbit by the administration of oestrogen. 7. exp. Zool. 135, 461.

Greenwald, G. S. (1959) The comparative effectiveness of estrogens in interrupting pregnancy in the rabbit. Fert. Steril. 10, 155.

Greenwald, G. S. (1961) The antifertility effects in pregnant rats of a single injection of estradiol cyclopentylpropionate. Endocrinology, 69, 1068.

HARPER, M. J. K. (1964) The effects of constant doses of oestrogen and progesterone on transport of artificial eggs through the reproductive tract of ovariectomised rabbits. F. Endocr. 30, 1.

LERNER, L. J. (1964) Hormone antagonists. Inhibitor of specific activities of oestrogen and androgen. Recent Progr. Horm. Res. 20, 435. 
Noyes, R. W., Adams, G. E. \& Walton, A. (1959) The transport of ova in relation to the dosage of oestrogen in ovariectomised rabbits. F. Endocr. 18, 108.

Pincus, G. \& BantK, U. K. (1963) Anti-progestins and implantation. Proc. VIIth int. Conf. Planned Parenthood. Excerpta Medica, Series No. 72, 588.

Pincts, G., Banik, U. K. \& Jaceues, J. (1964) Further studies on implantation inhibitors. Steroids, 4, 658 .

Prasad, M. R. N., Kalra, S. P. \& Segal, S. J. (1965) Effect of clomiphene on blastocysts during delayed implantation in the rat. Fert. Steril. 16, 101.

Roy, S., Greenblatt, R. B. \& Mahesh, V. B. (1964) Effects of clomiphene on the physiology of reproduction in the rat. II. Its oestrogenic and anti-oestrogenic actions. Acta endocr., Copenh. 47, 657.

Roy, S., Mahesh, V. B. \& Greenblatt, R. B. (1964) Effects of clomiphene on the physiology of reproduction in the rat. III. Inhibitor of uptake of radioactive oestradiol by the uterus and pituitary glands of immature rat. Acta endocr., Copenh. 47, 669.

Schlough, J. S. \& MEYER, R. K. (1965a) Effect of anti-estrogens on estrogen-induced ova implantation in the ovariectomised rat. Fert. Steril. 16, 106.

Schlough, J. S. \& MEYER, R. K. (1965b) Suppression of decidual response with estrogen antagonists. Fert. Steril. 16, 596.

Segal, S. J. \& Nelson, W. O. (1961) Antifertility action of chloramiphene. Anat. Rec. 139, 273.

SHELESNYAK, M. G. (1957) Some experimental studies on the mechanism of ova-implantation in the rat. Recent Progr. Horm. Res. 13, 269.

Shelesnyak, M. G., Kraicer, P. F. \& Zeilmaker, G. H. (1963) Studies on the mechanism of decidualization. I. The oestrogen surge of pseudopregnancy and progravidity and its role in the process of decidualization. Acta endocr., Copenh. 42, 225.

Staples, R. E. (1966) Effect of clomiphene on blastocyst nidation in the rat. Endocrinolog', 78, 82. 